\title{
Dynamic Impact Absorption Behaviour of Glass Coated with Carbon Nanotubes
}

\author{
Prashant Jindal $^{1 *}$, Meenakshi Goyal ${ }^{2}$, Navin Kumar ${ }^{3}$ \\ ${ }^{1}$ University Institute of Engineering \& Technology, Panjab University, Chandigarh, India; ${ }^{2}$ University Institute of Chemical Engi- \\ neering \& Technology, Panjab University, Chandigarh, India; ${ }^{3}$ Indian Institute of Technology, Roopnagar, Punjab, India. \\ Email: jindalp@pu.ac.in
}

Received July $3^{\text {rd }}, 2013$; revised August $5^{\text {th }}, 2013$; accepted September $1^{\text {st }}, 2013$

Copyright (C) 2013 Prashant Jindal et al. This is an open access article distributed under the Creative Commons Attribution License, which permits unrestricted use, distribution, and reproduction in any medium, provided the original work is properly cited.

\begin{abstract}
Boro-silicate glass samples were coated with chemically treated multi-walled carbon nanotubes (MWCNTs) to study the resistance offered by the coatings under the high strain rate impact. Impact testing of these glass samples was performed on Split Hopkinson Pressure Bar (SHPB), where strain rates were varied from 500/s to 3300/s. However, the comparisons were limited to samples subjected to a strain rate of $2300 / \mathrm{s}$ to $3000 / \mathrm{s}$ so that the effect of only variable deposits of coatings on the stress-strain behavior of glass can be studied. Variable deposits $(0.1 \mathrm{mg}$ to $0.8 \mathrm{mg}) \mathrm{of}$ MWCNTs were coated uniformly on glass samples having a disc shape with a fixed surface area $\left(79 \mathrm{~mm}^{2}\right)$ to observe the effect of the coating on the impact absorption capacity of glass. It was observed that the small thickness of about 25 $\mu \mathrm{m}$ formed due to the fact that $0.2 \mathrm{mg}$ of MWCNTs deposit spread over the surface increased the impact absorption capacity of the glass pieces by nearly $70 \%$. However, beyond this amount when the deposit was increased to $0.4 \mathrm{mg}$, the coating thickness got doubled to nearly $49 \mu \mathrm{m}$ and this led to a fall in absorption capacity which remained static till $0.8 \mathrm{mg}$ deposit. However, even this decrease in capacity was able to absorb $30 \%$ more impact than offered by pure glass sample.
\end{abstract}

Keywords: Glass Coatings; Impact Behaviour; Strength; Mechanical Properties

\section{Introduction}

Over the years, impacting resistant materials has been extensively studied using composites that comprise of light weight base matrix and strong filler materials. These materials are tested under extreme impact and static loading conditions so that they can be used for various applications like bullet-proof shields, jackets, resistant surfaces, shock and impact absorbers etc. [1,2].

Apart from fabricating stress resistant materials in the form of composites, absorber coatings also become important when it comes to preserving the basic equipment and acting as a protective coat. These coatings can be sacrificed to protect the base material also. It becomes imperative that such coatings are their light weight so that their own weight does not affect the overall utility of the basic equipment.

One of the most useful equipments for studying material behavior under impact loading is Split Hopkinson Pressure Bar (SHPB). Stress-strain behavior of the specimen when subjected to impact or dynamic loading is

*Corresponding author. obtained when the specimen is subjected to a strain rate of 100 to $10,000 / \mathrm{s}$.

The SHPB apparatus consists of two long slender bars namely, an input bar and an output bar that sandwich a short specimen between them. Whenever any load is applied on one end, the sandwiched specimen undergoes very high compression loading. A block diagram of a typical SHPB is shown in Figure 1.

The details of working of Split Hopkinson bar set up are widely available in literature [3]. It is basically based upon the measurement of wave signal which is generated by the input and output bars due to high strain rate loading. The waves are a measure of strains which are calibrated to find stress and strain in the specimen and in an earlier work. Impact loading using SHPB on carbon nanotube-polycarbonate composites was also studied [4].

To the best of our knowledge, most of the dynamic and quasi-static strength related work has been done on composite structures [4-9]. Static properties like elastic modulus, indentation pressure and fracture toughness of coatings on glass have been studied by Malzbender et al. $[10,11]$. In these studies, the composition of the coat- 
ings has also been varied by silica and alumina composition. Fluid based coatings like methyltrimethoxysilane and Ludox were also used. Coatings of thickness nearly $5 \mu \mathrm{m}$ to $11 \mu \mathrm{m}$ have also been studied. Static load in the order of $50 \mathrm{mN}$ to $300 \mathrm{mN}$ was applied and observations were measured on the basis of indentations made on the surface. Indentation pressures were greatly reduced after the initiation of any crack or indentation. However, the results have been used only as guidance on how crack. Delamination and chipping of coatings takes place as applied static load is varied.

Thus no study has appeared in the literature that uses a coating of MWCNTs instead of embedding for dynamical impact study. Since MWCNTs have anisotropic behaviors even for elastic properties, these offer great possibilities as protective fronts to soft targets. The Young's modulus as well as tensile strength is significantly different as compared to their bulk modulus $[12,13]$. Therefore a study that uses vertically aligned coatings as fronts is expected to behave differently as compared to horizontally aligned coating fronts. Usually it is very difficult to control up till now the alignment of carbon nanotubes, therefore a mixture is expected. For horizontally aligned, resilience of carbon nanotubes is also going to be useful. With this objective in view, we have planned to undertake the present study which aimed to study the modification of resistance offered by pure glass on exposing carbon nanotubes coated surface to the impact. We have prepared variable thickness of coatings of MWCNTs by varying the quantity of deposit on glass and studied them under the high strain rate impact. We have given an experimental methodology for sample preparation. The coating procedure is defined and these samples are then subjected to impact studies using SHPB. In the end, the work is summarized and concluded.

\section{Experimental}

MWCNTs having diameter about $10-30 \mathrm{~nm}$ and length 1 - 10 microns were procured from Nanoshel Intelligent Materials Pvt. Ltd., USA. We characterized them using FTIR spectra as shown in Figure 2 and the peaks are indicative of the MWCNTs. Figure 3 shows the SEM image of MWCNTs as provided by the supplier. The image indicates the diameter of the material as per specifications.

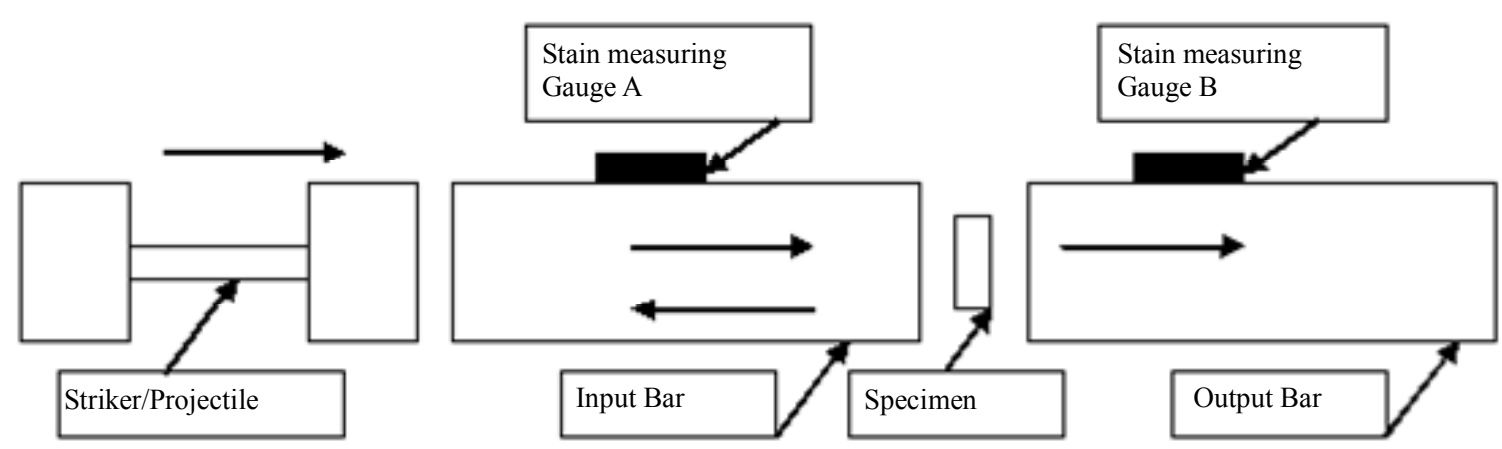

Figure 1. Schematic block diagram of split hopkinson pressure bar.

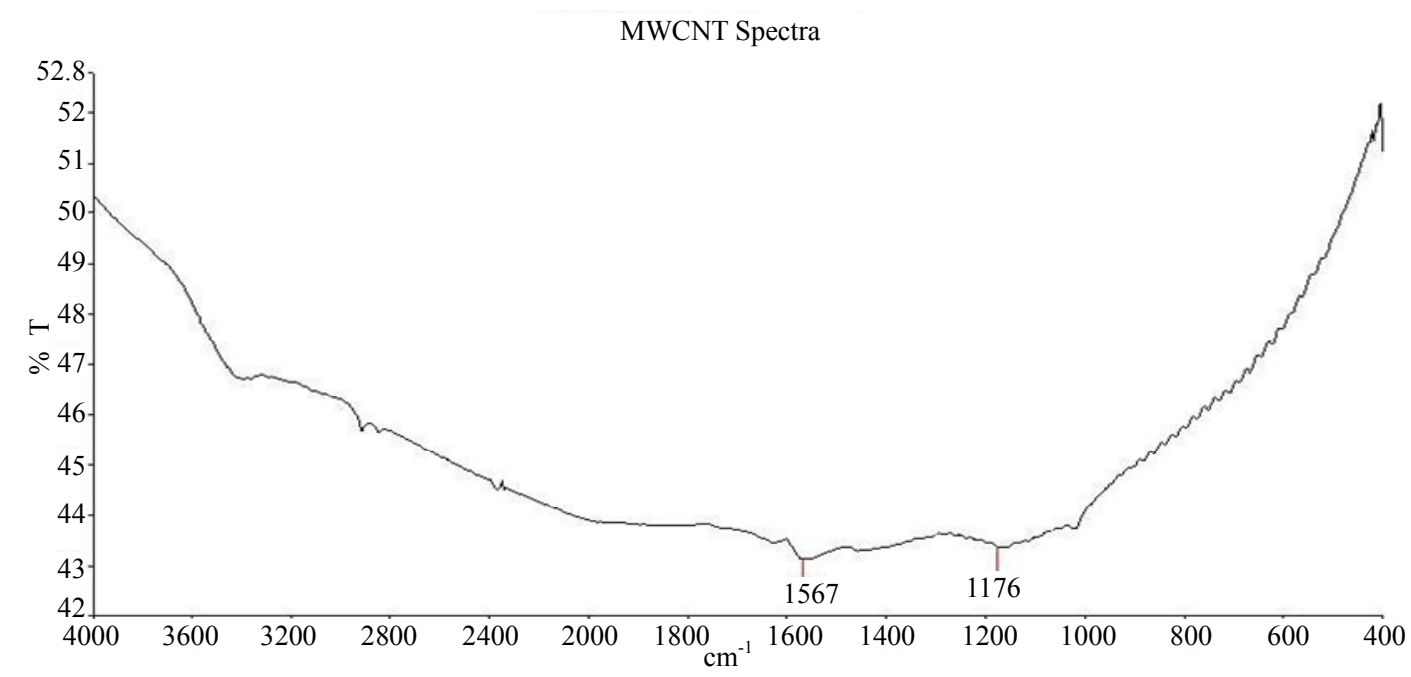

Figure 2. FTIR spectra for MWCNTs purchased from Nanoshel Intelligent Materials Pvt. Ltd. 


\section{Coating Procedure}

Boro-silicate glass pieces of disc shape having diameter $10 \mathrm{~mm}$ and thickness $5 \mathrm{~mm}$ were taken as the base material. They were cleaned with ethanol. MWCNTs of variable amounts were mixed with DMF (dimethylformamide) and ultra-sonicated for a few hours to ensure reasonable dispersion. Measured quantities of different concentrations of these MWCNTs solutions were then spread over the glass pieces to form non-covalent bond [14] between the coating and glass surface. The different concentrations of these MWCNTs solutions and amount spread over the glass pieces are given in Table 1. On evaporation of the solvent, coatings of varied thickness and quantity of MWCNTs distributed reasonably uniformly as solvent on the surface of glass samples of 79 $\mathrm{mm}^{2}$ area were obtained.

A simple estimate of a single layer of average thickness D of MWCNTs of bulk density $\rho$ when spread over a surface area A of the glass disc, will have mass as $\mathrm{m}=$ $\mathrm{AD} \rho$. The average bulk density of our MWNCTs was $100 \mathrm{mg} / \mathrm{cm}^{3}$, average length $=5 \mu \mathrm{m}, \mathrm{A}=0.79 \mathrm{~cm}^{2}$ and $\mathrm{m}$ $=0.1 \mathrm{mg}$ to $0.8 \mathrm{mg}$ meant that for our samples the thickness was from 10 to $100 \mu \mathrm{m}$. It also meant that our samples were coated with about 5 to 20 layers. This way we can control the MWCNT layers to about 50 by varying the deposit of MWCNTs even if the MWCNTs stand vertically. The data of estimated number of layers is also presented in Table 1. It may be noted, that the number of layers is based upon the assumption that MWCNTs are vertically aligned, however in reality MWCNTs can be a combination of various alignments. Hence, the number of layers given is a lower estimate.

These different glass coated samples were then used for dynamic impact strength studies and their dynamic impact strengths were compared at high strain rates using SHPB. The variation parameter here was only the amount of coating deposited not the geometry or orientation of the inner structure of specimen.

The setup for SHPB comprised of two high strength maraging steel with yield strength $\sim 1750 \mathrm{MPa}$, diameter $20 \mathrm{~mm}$ and length $2000 \mathrm{~mm}$. The projectile diameter was $20 \mathrm{~mm}$ and length was $300 \mathrm{~mm}$. Strain gauges of $120 \Omega$,
900 tee rosette precision stain gauges designated as EA06-125TM-120) were used.

Projectile of length $300 \mathrm{~mm}$ was hit on samples of different deposits one by one which were sandwiched between the two bars.

The projectile was shot at by a pressure gun producing stress-strain curves for different strain rates. Strain rates varied in the range from $500 / \mathrm{s}$ to $3300 / \mathrm{s}$.

\section{Results and Discussion}

The data collected by strain gauges for incident, reflected and transmitted signals leads to evaluation of stress-strain data. Though stress-strain data was obtained for a wide range of strain rates (500/s to 3300/s) for all samples but samples which were limited to a strain rate of 2300 /s to $3000 / \mathrm{s}$ were compared so that the effect of only variable deposits of coatings on the stress-strain behavior of glass could be studied. This strain rate is a useful range in normal shock conditions, encountered during aviation and defense requirements [15]. Compressive stress-strain behavior for glass pieces coated with MWCNTs of different amount at strain rates of about $2500 / \mathrm{s}$ are shown in Figure 4.

It is observed from Figure 4 that a plastic deformation pattern is formed for all samples.

Maximum stress absorbed by each of these samples shows that till a particular deposit of coating, there is a substantial increase in the stress absorbed but after that it starts decreasing. Maximum stress absorbed for pure glass is nearly $389 \mathrm{MPa}$. When this piece is non-covalently bonded with $0.1 \mathrm{mg}$ of MWCNT coating then this

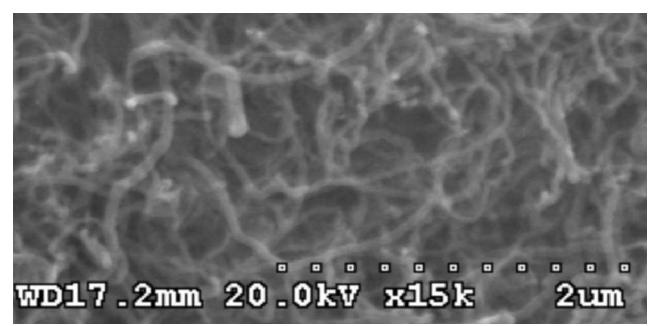

Figure 3. SEM Image for MWCNTs as provided by Nanoshel Intelligent Materials Pvt. Ltd.

Table 1. Samples of various concentrations of MWCNTs solution on glass, thickness of coat, rough estimate of number of layers and quantity of solution that was spread on glass surface.

\begin{tabular}{ccccc}
\hline Sample No. & $\begin{array}{c}\text { Concentration of coating on glass } \\
(\mathbf{m g} / \mathbf{\mu L})\end{array}$ & $\begin{array}{c}\text { Quantity of solution poured } \\
(\boldsymbol{\mu} \mathbf{L})\end{array}$ & $\begin{array}{c}\text { Coating thickness } \\
(\boldsymbol{\mu m})\end{array}$ & $\begin{array}{c}\text { Estimated no. } \\
\text { of layers }\end{array}$ \\
\hline 1 & $10 / 1000$ & 10 & 12 & 3 \\
2 & $18.6 / 930$ & 10 & 25 & 5 \\
3 & $20 / 520$ & 10 & 49 & 10 \\
4 & $25 / 400$ & 10 & 80 & 16 \\
5 & $15 / 200$ & 10 & 95 & 19 \\
\hline
\end{tabular}




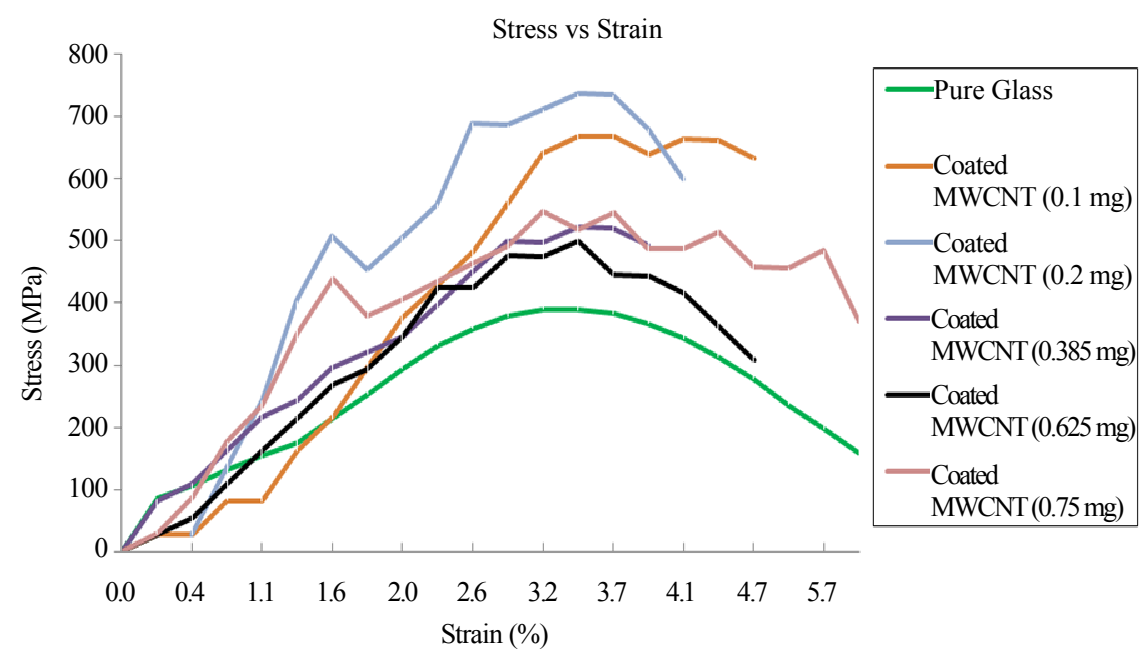

Figure 4. Variation of stress strain for different amounts of coated glass pieces with MWCNTs subjected to strain rates from $2300 / \mathrm{s}$ to $3000 / \mathrm{s}$.

maximum limit reaches $667 \mathrm{MPa}$ at nearly the same strain. Similarly, for $0.2 \mathrm{mg}$ coating the stress value is about 736 MPa. But beyond this, for coatings of $0.385 \mathrm{mg}, 0.625$ $\mathrm{mg}$ and $0.75 \mathrm{mg}$ this maximum stress value remains nearly same $500 \mathrm{MPa}$ which is still much higher than pure glass.

So, in comparison to pure glass, the samples which were coated with a very small amount of $0.1 \mathrm{mg}$ and $0.2 \mathrm{mg}$ MWCNTs had about $50 \%$ to $70 \%$ increased stress absorption capacity. This also implies that a coating thickness of MWCNTs of about $12 \mu \mathrm{m}$ to $25 \mu \mathrm{m}$ is sufficient to enhance the stress absorption by almost 2 times.

However, the improved degradation at higher concentration is most likely to be a result of slipping of the layers among themselves as contact with glass gets lost because coatings of nearly 0.4 to $0.8 \mathrm{mg}$ means that thickness of coatings reaches nearly $40 \mu \mathrm{m}$ to $100 \mu \mathrm{m}$. So, the number of layers on the glass pieces increases accordingly.

The effect of variation in deposit of MWCNT coatings on maximum impact stress within the strain rates at about 2500/s as explained above is further depicted in Figure 5.

\section{Summary and Conclusion}

Base materials which have attractive properties like light weight, mould ability, transparency etc. but are vulnerable to impact or shock loads need to be improved in terms of their dynamic strength by either embedding or coating with other stronger materials. In this paper we studied the dynamic impact absorption using SHPB of pure boro-silicate glass as the base material and the same glass coated with variable amounts of MWCNTs.

Boro-silicate glass in the form of a disc $10 \mathrm{~mm}$ diameter and $5 \mathrm{~mm}$ thickness was used as the base material.

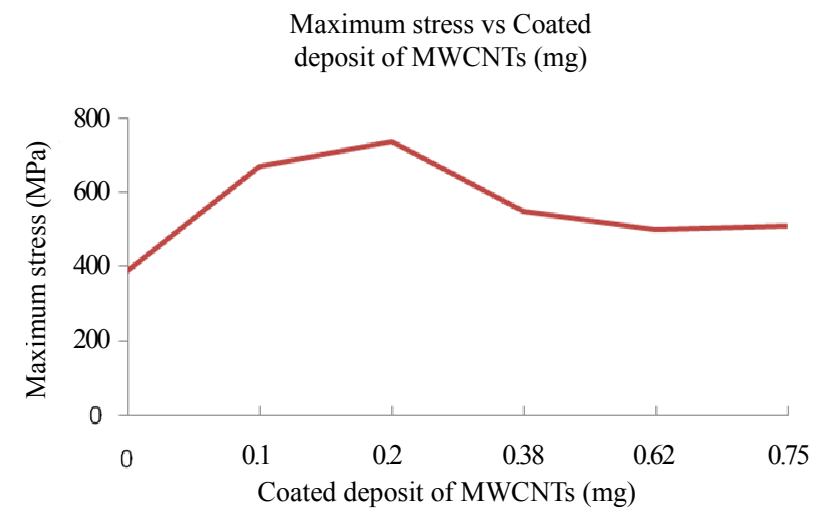

Figure 5. Maximum stress variation with different coated MWCNTs-glass samples subjected to strain rates from $2300 / \mathrm{s}$ to $3000 / \mathrm{s}$.

Coated samples were prepared using non-covalent chemical binding techniques. The coated amount of MWCNTs was varied from $0.1 \mathrm{mg}$ to $0.8 \mathrm{mg}$ and accordingly thickness of the coating was also estimated. For smaller concentrations, the thickness of $12 \mu \mathrm{m}$ to $25 \mu \mathrm{m}$ meant that the number of layers on the glass surface was nearly 5 . But for the higher amount of coatings as the thickness of coating increased to about $100 \mu \mathrm{m}$, the layers also reach about 20.

Dynamic impact was applied to these samples and interesting observations were made. Samples which had coatings of about $0.1 \mathrm{mg}$ and $0.2 \mathrm{mg}$ showed significant increase in the maximum stress absorption in comparison to pure glass. The increase was about $50 \%$ to $70 \%$. Maximum stress for $0.1 \mathrm{mg}$ and $0.2 \mathrm{mg}$ coating sample was nearly $689 \mathrm{MPa}$ and $736 \mathrm{MPa}$ respectively while pure glass maximum stress was $389 \mathrm{MPa}$. However, coatings of nearly $0.4 \mathrm{mg}, 0.6 \mathrm{mg}$ and $0.8 \mathrm{mg}$ did not show a further increase. The maximum stress absorbed by these samples 
was nearly $500 \mathrm{MPa}$, which was still about $30 \%$ higher than pure glass but much less than $0.1 \mathrm{mg}$ and $0.2 \mathrm{mg}$. The reason for this reduction can be the increased thickness of coating that comprises of multiple layers of MWCNTs.

As layers of coatings increase, there is slipping of these layers from the glass surface and amongst the layers themselves. As a result, the coatings slip away from the base glass surface and fail to offer higher resistance to impact.

On the basis of the results obtained in this work, it seems safe to conclude that coating by small concentrations of MWCNT improves the dynamic impact strength of glass.

It not only helps modify glass strength, but also is a useful impact stress sensor. In fact, a stacking of multiple coated glass samples can be used to absorb desired impact as well as sensing unit for such impacts. As the glass piece was covered with minor amounts of MWCNTs, the transparency loss was not significant.

\section{Acknowledgements}

Prashant Jindal gratefully acknowledges financial support from the Defence Research Organization (DRDO) for a research project (No. ARMREB/DSW/2011/129). $\mathrm{He}$ also acknowledges the Director, TBRL and the whole team of Gun Group for extending their lab facilities. Guidance provided by Biomoluecular Electronics and Nanotechnology Division (BEND), at Central Scientific Instruments Organisation (CSIO), Chandigarh is also acknowledged. He is also grateful to Mr. Hitesh Sharma from Accurate Optics, Chandigarh for assistance in providing base material. Dr. Rajesh Kumar, UIET, Panjab University, Chandigarh assistance is also acknowledged.

\section{REFERENCES}

[1] J. N. Coleman, U. Khan, W. J. Blau and Y. K. Gun'ko, "Small but Strong: A Review of the Mechanical Properties of Carbon Nanotube-Polymer Composites," Carbon, Vol. 44, No. 9, 2006, pp. 1624-1652. http://dx.doi.org/10.1016/j.carbon.2006.02.038

[2] P. Raju Mantena, Alexander H. D. Cheng, Ahmed Al-Ostaz and A. M. Rajendran, "Blast and Impact Resistant Composite Structures for Navy Ships Composite Structures and Nano-Engineering Research" Proceedings of the 2008 ONR Solid Mechanics Program-Marine Composites and Sandwich Structures, University of Maryland, Adelphi, 2009, pp. 417-426.

[3] H. Kolsky, "An Investigation of the Mechanical Properties of Materials at Very High Rates of Loading," Proceedings of the Royal Society of London, London, B62, 1949, pp. 676-700

[4] P. Jindal, S. Pande, P. Sharma, V. Mangla, A. Chaudhury,
Deepak Patel, B. P. Singh, R. B. Mathur and M. Goyal, "High Strain Rate Behavior of Multi-Walled Carbon Nanotubes-Polycarbonate Composites," Composites Part B: Engineering, Vol. 45, No. 1, 2013, pp. 417-422. http://dx.doi.org/10.1016/j.compositesb.2012.06.018

[5] N. K. Naik and Y. Perla, "Mechanical Behaviour of Acrylic under High Strain Rate Tensile Loading," Polymer Testing, Vol. 27, No. 4, 2008, pp. 504-512. http://dx.doi.org/10.1016/j.polymertesting.2008.02.005

[6] A. Jadhav, E. Woldesenbet and S.-S. Pang, "High Strain Rate Properties of Balanced Angle-Ply Graphite/Epoxy Composites," Composites: Part B, Vol. 34, No. 4, 2003, pp. 339-346.

http://dx.doi.org/10.1016/S1359-8368(03)00003-9

[7] W. Chen, F. Lu and M. Cheng, "Tension and Compression Tests of Two Polymers under Quasistatic and Dynamic Loading," Polymer Testing, Vol. 21, No. 2, 2002, pp. 113-121.

http://dx.doi.org/10.1016/S0142-9418(01)00055-1

[8] R. B. Mathur, S. Pande, B. P. Singh and T. L. Dhami, "Electrical and Mechanical Properties of Multi-Walled Carbon Nanotubes Reinforced PMMA and PS Composites," Polymer Composites, Vol. 29, No. 7, 2008, pp. 717-727. http://dx.doi.org/10.1002/pc.20449

[9] Y. H. Xu, Q. F. Li, D. Sun, W. N. Zhang and G.-X. Chen, "A Strategy to Functionalize the Carbon Nanotubes and the Nanocomposites Based on Poly(L-lactide)," Industrial \& Engineering Chemistry Research, Vol. 51, No. 42, 2012, pp. 13648-13654.

http://dx.doi.org/10.1021/ie300989w

[10] J. Malzbender, G. de With and J. M. J. den Toonder, "Elastic Modulus, Indentation Pressure and Fracture Toughness of Hybrid Coatings on Glass," Thin Solid Films, Vol. 366, No. 1-2, 2000, pp. 139-149. http://dx.doi.org/10.1016/S0040-6090(00)00656-8

[11] J. Malzbender and G. de With, "Energy Dissipation, Fracture Toughness and the Indentation Load-Displacement Curve for Coated Materials," Surface and Coatings Technology, Vol. 135, No. 1, 2000, pp. 60-68. http://dx.doi.org/10.1016/S0257-8972(00)00906-3

[12] R. S. Ruoff, D. Qian and W. K. Liu, "Mechanical Properties of Carbon Nanotubes: Theoretical Predictions and Experimental Measurements," C. R. Physique, Vol. 4, No. 9, 2003, pp. 993-1008. http://dx.doi.org/10.1016/j.crhy.2003.08.001

[13] A. Sears and R. C. Batra, "Macroscopic Properties of Carbon Nanotubes from Molecular-Mechanics Simulations," Physical Review B, Vol. 69, 2004, Article ID: 235406.

[14] Ma, A. Lu, J. Yang, S. H. Ka and M. Ng, "Quantitative Non-Covalent Functionalization of Carbon Nanotubes," Journal of Cluster Science, Vol. 17, No. 4, 2006, pp. 599608. http://dx.doi.org/10.1007/s10876-006-0076-7

[15] Mostafa Shazly, David Nathenson and Vikas Prakash, "Modelling of High Strain Rate Deformation, Fracture and Impact Behavior of Advances Gas Turbine Engine Materials at Low and Elevated Temperatures," 2003, NASA CR-2003-212194. 